Review Article

\title{
Nonalcoholic Fatty Liver Disease and Type 2 Diabetes Mellitus: A Bidirectional Relationship
}

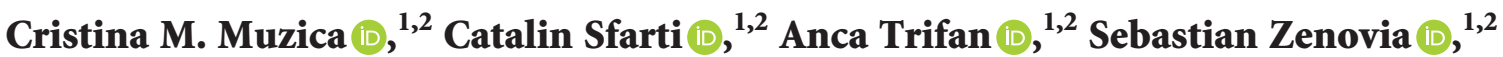 \\ Tudor Cuciureanu $\mathbb{D}^{1,2}$ Robert Nastasa ${ }^{1 D},{ }^{1,2}$ Laura Huiban $\mathbb{D D}^{1,2}$ Camelia Cojocariu (D), ${ }^{1,2}$ \\ Ana-Maria Singeap $\mathbb{D},{ }^{1,2}$ Irina Girleanu $\mathbb{D},{ }^{1,2}$ Stefan Chiriac $\mathbb{D}$, ${ }^{1,2}$ and Carol Stanciu $\mathbb{D}^{2}$ \\ ${ }^{1}$ Department of Gastroenterology, Grigore T. Popa University of Medicine and Pharmacy, Iasi 700115, Romania \\ ${ }^{2}$ St. Spiridon Emergency Hospital, Iasi 700115, Romania
}

Correspondence should be addressed to Anca Trifan; ancatrifan@yahoo.com and Sebastian Zenovia; sebastianzenovia20@gmail.com

Received 20 November 2020; Accepted 15 December 2020; Published 28 December 2020

Academic Editor: Branka Filipović

Copyright (c) 2020 Cristina M. Muzica et al. This is an open access article distributed under the Creative Commons Attribution License, which permits unrestricted use, distribution, and reproduction in any medium, provided the original work is properly cited.

\begin{abstract}
Worldwide, the leading cause of chronic liver disease is represented by nonalcoholic fatty liver disease (NAFLD) which has now become a global epidemic of the 21st century, affecting 1 in 4 adults, and which appears to be associated with the steadily increasing rates of metabolic syndrome and its components (obesity, type 2 diabetes mellitus (T2DM), and dyslipidemia). NAFLD has been reported to be associated with extrahepatic manifestations such as cardiovascular disease, T2DM, chronic kidney disease, extrahepatic malignancies (e.g., colorectal cancer), endocrine diseases (e.g., hypothyroidism, polycystic ovarian syndrome, psoriasis, and osteoporosis), obstructive sleep apnea, and iron overload. The prevalence of NAFLD is very high, affecting $25-30 \%$ of the world population and encloses two steps: (1) nonalcoholic fatty liver (NAFL), which includes steatosis only, and (2) nonalcoholic steatohepatitis (NASH) defined by the presence of steatosis and inflammation with hepatocyte ballooning, with or without fibrosis which can progress to liver fibrosis, hepatocellular carcinoma, and liver transplantation. Current data define a more complex relationship between NAFLD and T2DM than was previously believed, underlining a bidirectional and mutual association between the two entities. This review aims to summarize the current literature regarding the incidence of T2DM among patients with NAFLD and also the prevalence of NAFLD in T2DM patients, highlighting the recent key studies. Clinicians should screen, diagnose, and treat T2DM in patients with NAFLD in order to avoid short- and long-term complications.
\end{abstract}

\section{Introduction}

The incidence rate of chronic liver diseases increased through the years with a worrying rise of liver-related morbidity and mortality rates worldwide [1]. One of the major causes of chronic liver diseases is represented by nonalcoholic fatty liver disease (NAFLD) which has now become a global epidemic affecting 1 in 4 adults, with an estimated prevalence between $25 \%$ and $30 \%$, and appears to be associated with the steadily increasing rates of metabolic syndrome (MetS) and its components (obesity, type 2 diabetes mellitus (T2DM), and dyslipidemia) [1-3]. The mandatory feature of NAFLD is the presence of liver steatosis (LS) in the absence of other causes of chronic liver disease [4]. Although initially NAFLD was considered as the hepatic manifestation of MetS, there is now clear evidence that NAFLD is a key driver in MetS and hepatic involvement is only one component of systemic multiorgan involvement $[5,6]$. NAFLD encloses two distinct conditions with different histologic features and prognosis: (1) nonalcoholic fatty liver (NAFL), which includes steatosis only, and (2) nonalcoholic steatohepatitis (NASH) characterized by steatosis and inflammation with hepatocyte ballooning, with or without fibrosis, which can progress to liver fibrosis (LF), cirrhosis, hepatocellular carcinoma (HCC), and liver transplantation [7]. The prevalence of NASH among 
NAFLD patients ranges from $10 \%$ to $59 \%$ in patients who underwent liver biopsy [1], meaning that millions and millions of people worldwide are at risk of cirrhosis and its complications. Even more alarming is that the continuously increasing rates of MetS and its components parallel the rising prevalence of NASH, with obesity, T2DM, and MetS being the most important risk factors $[8,9]$.

Growing evidence clearly shows that NAFLD is a multiorgan disease, supporting a strong link between NAFLD and cardiovascular diseases (CVDs), T2DM, chronic kidney disease (CKD), extrahepatic malignancies (eg., colorectal cancer), obstructive sleep apnea (OSA), and various endocrinopathies (e.g., thyroid dysfunction, polycystic ovarian syndrome (PCOS), osteoporosis, psoriasis, hypothyroidism, and iron overload) $[10,11]$. Although the primary site of NAFLD is the liver, the most common causes of mortality are CVDs, followed by extrahepatic malignancies such as colorectal cancer and then liver-related complications (cirrhosis and HCC) $[5,6,12]$. Considering the high clinical and economic burden of NAFLD, the main point in the management of these patients is an early acknowledgement of both hepatic and extrahepatic manifestations and their subsequent complications $[11,13,14]$. Current data outline a more complex relationship between NAFLD and T2DM than was previously thought, pointing out a bidirectional and mutual association between the two entities. Thus, clinicians should screen, diagnose, and treat T2DM in patients with NAFLD in order to avoid short- and long-term complications. Herein, this review aims to summarize the current literature regarding the incidence of T2DM among patients with NAFLD and also the prevalence of NAFLD in T2DM patients, highlighting recent key studies.

\section{Relation between NAFLD and T2DM}

Current data reveal a more complex relationship between NAFLD and T2DM than was previously believed, highlighting a bidirectional and mutual association between the two entities $[11,15,16]$. Considering that NAFLD and T2DM have similar physiopathological pathways, one can precede and/or promote the other [10, 17].

2.1. T2DM in Patients with NAFLD. NAFLD is associated with lipotoxicity which is secondary to the accumulation of triglyceride-derived toxic metabolites in the liver, pancreas, and muscles, which leads to the activation of the inflammation cascade and insulin resistance $[18,19]$. The hepatic insulin resistance associated with NAFLD is the key driver for the development of T2DM among these patients.

The prevalence of T2DM in patients with NAFLD depends on the severity of NAFLD starting from $9.8 \%$ in mild NAFLD to $17.8 \%$ in moderate to severe NAFLD [20-22]. Although NAFLD is considered an independent risk factor for developing T2DM, with a 2-fold incidence increase in these individuals, patients with NASH have an up to threefold higher risk of developing incident T2DM compared with those with simple steatosis [20, 23, 24].

Despite evidence from several studies which demonstrated that high levels of NAFLD's surrogate markers-gamma-glutamyl transferase and alanine aminotransferase (ALT) - were associated with a high incidence of T2DM, the predictive value of these biologic parameters is limited due to the possibility of normal levels among these patients [25-29]. As for ultrasonography-defined NAFLD (liver steatosis $\geq 20 \%$ ) $[30,31]$, recent data showed a twofold to fivefold increased risk of T2DM [32].

Many large-population-based retrospective studies with a follow-up period of 3 to 6.2 years showed an increased incidence risk of T2DM among patients diagnosed with NAFLD (Table 1) [33-37, 42, 43]. Shibata et al. achieved a 4-year follow-up in 3189 patients among whom 1138 had NAFLD at baseline and reported an incidence of $1.8 \%$ vs. $8.1 \%$ in the non-NAFLD patients compared with those with NAFLD [33]. Similarly, 4 other retrospective studies which included Asian cohorts without T2DM, demonstrated that NAFLD was significantly associated with a high incidence of T2DM during follow-up [34-37]. In a similar manner, prospective studies which evaluated the prevalence of T2DM among patients with NAFLD have also reported an increased risk associated with baseline NAFLD [38-41]. Results from an Israeli cohort of 141 nondiabetic participants among which $24.8 \%$ had NAFLD, followed up for an average period of $6.08 \pm 0.7$ years, demonstrated a higher incidence of prediabetes and/or T2DM in patients with NAFLD than in subjects without NAFLD (74.3\% vs. $48.1 \%)$ [39]. In a recent retrospective study conducted by Liu et al. which included 18,507 nondiabetic subjects, the prevalence of NAFLD was $18.77 \%$ with a 5 -year T2DM incidence of $2.44 \%$. The authors concluded that patients with baseline NAFLD had a higher risk incidence of T2DM, with an adjusted relative risk of 1.672 [43].

2.2. NAFLD in Patients with T2DM. Once established, T2DM may promote the progression to NASH and become an independent risk factor for chronic liver disease, including cirrhosis and HCC [10]. It has been reported that the presence of NAFLD among patients with T2DM determined a 2.2-fold risk increase in all-cause mortality, compared with those without NAFLD [15]. The estimated prevalence of NAFLD among patients with T2DM is about $75 \%$, which is more than the prevalence in the general population [1].

Evidences from several recent cohort studies highlighted an increased incidence of NAFLD among patients diagnosed with T2DM, with an estimated prevalence ranging between $41.6 \%$ and $86 \%$ (Table 2) [8, 44-49]. For instance, Sporea et al. conducted a prospective study in which 534 patients diagnosed with T2DM were included. Patients with other causes of steatosis were excluded, and LF and steatosis were quantitatively assessed using vibration controlled transient elastography and the controlled attenuation parameter. The authors found an estimated prevalence of NAFLD of $76.1 \%$. Moreover, severe steatosis was detected in $60.3 \%$, while advanced LF had a prevalence of almost 20\% [50]. Two other retrospective studies reported a similar prevalence of NAFLD among T2DM patients $[45,46]$. 
TABLE 1: Studies which assessed T2DM incidence among patients with NAFLD.

\begin{tabular}{|c|c|c|c|}
\hline Ref. & Study design and period of surveillance & NAFLD assessment & $\begin{array}{c}\text { Cases with T2DM; \% in NAFLD vs. } \\
\text { non-NAFLD }\end{array}$ \\
\hline $\begin{array}{l}\text { Shibata et al. } 2007 \\
\text { [33] }\end{array}$ & $\begin{array}{c}\text { Retrospective cohort study; } n=3,189 \text { (33.6\% with } \\
\text { NAFLD); male Japanese; } 4 \text { years }\end{array}$ & Liver ultrasonography & $n=109$ incident cases; $1.8 \%$ vs. $8.1 \%$ \\
\hline $\begin{array}{l}\text { Kim et al. } 2008 \\
{[34]}\end{array}$ & $\begin{array}{c}\text { Retrospective cohort study; } n=5,372(33.3 \% \text { with } \\
\text { NAFLD); South Korean subjects without diabetes; } 5 \\
\text { years }\end{array}$ & Liver ultrasonography & $n=234$ incident cases; $2.3 \%$ vs. $8.5 \%$ \\
\hline $\begin{array}{l}\text { Bae et al. } 2011 \\
{[35]}\end{array}$ & $\begin{array}{c}\text { Retrospective study; } n=7,849 \text { ( } 29.2 \% \text { with NAFLD); } \\
\text { subjects without diabetes; } 5 \text { years }\end{array}$ & Liver ultrasonography & $n=435$ incident cases; $3.7 \%$ vs. $9.9 \%$ \\
\hline $\begin{array}{l}\text { Sung et al. } 2012 \\
{[36]}\end{array}$ & $\begin{array}{l}\text { Retrospective cohort study; } n=12,853 \text { ( } 27.6 \% \text { with } \\
\text { NAFLD); subjects without diabetes; } 5 \text { years }\end{array}$ & Liver ultrasonography & $n=223$ incident cases; $0.8 \%$ vs. $4.3 \%$ \\
\hline $\begin{array}{l}\text { Kasturirante et al. } \\
2013 \text { [37] }\end{array}$ & $\begin{array}{l}\text { Retrospective cohort study; } n=2,276 \text { ( } \\
\text { NAFLD); individuals without diabetes }\end{array}$ & Liver ultrasonography & $n=242$ incident cases; $10.5 \%$ vs. $19.7 \%$ \\
\hline $\begin{array}{l}\text { Park et al. } 2013 \\
{[38]}\end{array}$ & $\begin{array}{l}\text { Prospective cohort study; } n=25,232 \text { (35\% with } \\
\text { NAFLD); men without diabetes; } 5 \text { years }\end{array}$ & Liver ultrasonography & $\begin{array}{l}n=2,108 \text { incident cases; } 7 \% \text { in no } \\
\text { steatosis group vs. } 17.8 \% \text { in moderate } \\
\text { to severe steatosis group }\end{array}$ \\
\hline $\begin{array}{l}\text { Zelber-sagi et al. } \\
2013 \text { [39] }\end{array}$ & $\begin{array}{l}\text { Prospective cohort study, } n=213 \text {; without known } \\
\text { liver disease and alcohol abuse; } 7 \text { years }\end{array}$ & Liver ultrasonography & $n=106$ incident cases with NAFLD \\
\hline $\begin{array}{l}\text { Chen et al. } 2016 \\
\text { [40] }\end{array}$ & $\begin{array}{c}\text { Prospective cohort study; } n=6,542 \text {; Chinese subjects } \\
\text { without diabetes; } 6 \text { years }\end{array}$ & Liver ultrasonography & $n=368$ incident cases \\
\hline Li et al. 2017 [41] & $\begin{array}{l}\text { Prospective cohort study; } n=18,111 \text { (31.8\% with } \\
\text { NAFLD); Chinese subjects without diabetes without } \\
\text { known chronic liver diseases; } 4.6 \text { years follow-up }\end{array}$ & Liver ultrasonography & $\begin{array}{l}n=1,262 \text { incident cases; } 4.6 \% \text { in non- } \\
\text { NAFLD group vs. } 18.1 \text { in moderate to } \\
\text { severe NAFLD group }\end{array}$ \\
\hline Ma et al. 2017 [42] & $\begin{array}{l}\text { Retrospective cohort study; } n=1,051 \text { (17.8\% with } \\
\text { NAFLD); US individuals without diabetes without } \\
\text { known chronic liver diseases; } 6.2 \text { years }\end{array}$ & $\begin{array}{l}\text { Liver tomography and } \\
\text { ultrasonography }\end{array}$ & $n=64$ incident cases \\
\hline Liu et al. 2017 [43] & $\begin{array}{c}\text { Retrospective study, } n=18,507 \text {; men without } \\
\text { diabetes; } 5 \text { years }\end{array}$ & Liver ultrasonography & $n=453$ incident cases \\
\hline
\end{tabular}

NAFLD, nonalcoholic fatty liver disease; T2DM, type 2 diabetes mellitus.

TABLE 2: Studies which assessed NAFLD prevalence among patients with T2DM.

\begin{tabular}{lccc}
\hline Ref. & Study design; follow-up; and population & Diagnostic method of NAFLD & Prevalence of NAFLD \\
\hline Williamson et al. 2011 [8] & Retrospective study; $n=918 ; 1$ years & Ultrasound & $42,6 \%$ \\
Lv et al. 2013 [44] & Prospective cohort study; $n=1217 ; 4$ years & Ultrasound & $61 \%$ \\
Silaghi et al. 2015 [45] & Retrospective cohort study; $n=336 ;$ N/A & Ultrasound & $86 \%$ \\
Mantovani et al. 2016 [46] & Retrospective cohort study; $n=330 ; 2$ years & Ultrasound & $72,1 \%$ \\
Guo et al. 2017 [47] & Prospective cohort study; $n=8571 ; 9$ years & Ultrasound & $50,6 \%$ \\
Yi et al. 2017 [48] & Prospective cohort study; $n=3861 ; 1$ year & Ultrasound & $45,4 \%$ \\
Ding et al. 2017 [49] & Prospective cohort study; $n=1648 ; 1$ year & Ultrasound & $41,6 \%$ \\
Sporea et al. 2020 [50] & Prospective cohort study; $n=534 ;$ N/A & Ultrasound & $76,1 \%$ \\
\hline
\end{tabular}

NAFLD, nonalcoholic fatty liver disease; T2DM, type 2 diabetes mellitus; N/A, not available.

\section{Management of Patients with NAFLD and T2DM}

The reciprocal relationship between T2DM and NAFLD leads to the progression of LF and is secondary to the development of liver-related complications with high morbidity and mortality rates. In order to avoid systemic multicollateral damage, it seems appropriate to screen patients with NAFLD for T2DM, and vice-versa. According to current European Guidelines, screening of T2DM in patients with NAFLD is mandatory, and it consists of random blood glucose or hemoglobin A1C [51]. Furthermore, screening for NAFLD and LF is recommended by the American Diabetes Association in patients diagnosed with T2DM which have elevated liver enzymes (ALT) or LS, while the American Association Society of Liver Disease is not in favour of routine screening in these patients $[52,53]$.

\section{Conclusion}

In light of current evidence, the clinical burden of NAFLD is not limited to liver-related complications, but is in fact, related to its extrahepatic manifestations such as CVD, T2DM, CKD, extrahepatic malignancies, OSA, and various endocrinopathies, with increased mortality rates. Our review highlights that the components of NAFLD (NASH and NAFL) lead to insulin resistance and T2DM through various physiopathological pathways, but also T2DM may promote the progression to NASH as an independent risk factor. Thus, clinicians should be aware of these NAFLD-related extrahepatic manifestations considering that an early acknowledgement of $\mathrm{T} 2 \mathrm{DM}$ is the key point in the management of these patients. 


\section{Conflicts of Interest}

The authors declare no conflicts of interest in this work.

\section{Authors' Contributions}

All authors made substantial contributions to acquisition of data, or analysis, conception and design, and interpretation of data; took part in drafting of the article or revising it critically for important intellectual content; gave final approval of the version to be published; and agree to be accountable for all aspects of the work. All authors have read and agreed to the published version of the manuscript.

\section{References}

[1] Z. M. Younossi, A. B. Koenig, D. Abdelatif, Y. Fazel, L. Henry, and M. Wymer, "Global epidemiology of nonalcoholic fatty liver disease-meta-analytic assessment of prevalence, incidence, and outcomes," Hepatology, vol. 64, no. 1, pp. 73-84, 2016.

[2] C. D. Williams, J. Stengel, M. I. Asike et al., "Prevalence of nonalcoholic fatty liver disease and nonalcoholic steatohepatitis among a largely middle-aged population utilizing ultrasound and liver biopsy: a prospective study," Gastroenterology, vol. 140, no. 1, pp. 124-131, 2011.

[3] D. Kim, A. Touros, and W. R. Kim, "Nonalcoholic fatty liver disease and metabolic syndrome," Clinics in Liver Disease, vol. 22, no. 1, pp. 133-140, 2018.

[4] A. A. Li, A. Ahmed, and D. Kim, "Extrahepatic manifestations of nonalcoholic fatty liver disease," Gut and Liver, vol. 14, no. 2, pp. 168-178, 2020.

[5] L. A. Adams, J. F. Lymp, J. St. Sauver et al., "The natural history of nonalcoholic fatty liver disease: a population-based cohort study," Gastroenterology, vol. 129, no. 1, pp. 113-121, 2005.

[6] D. Kim, W. R. Kim, H. J. Kim, and T. M. Therneau, "Association between noninvasive fibrosis markers and mortality among adults with nonalcoholic fatty liver disease in the United States," Hepatology, vol. 57, no. 4, pp. 1357-1365, 2013.

[7] S. Singh, A. M. Allen, Z. Wang, L. J. Prokop, M. H. Murad, and R. Loomba, "Fibrosis progression in nonalcoholic fatty liver vs nonalcoholic steatohepatitis: a systematic review and metaanalysis of paired-biopsy studies," Clinical Gastroenterology and Hepatology, vol. 13, no. 4, pp. 643-654, 2015.

[8] R. M. Williamson, J. F. Price, S. Glancy et al., "Prevalence of and risk factors for hepatic steatosis and nonalcoholic fatty liver disease in people with type 2 diabetes: the edinburgh type 2 diabetes study," Diabetes Care, vol. 34, no. 5, pp. 1139-1144, 2011.

[9] Collaboration NCDRF, "Worldwide trends in body-mass index, underweight, overweight, and obesity from 1975 to 2016: a pooled analysis of 2416 population-based measurement studies in 128.9 million children, adolescents, and adults," Lancet, vol. 390, pp. 2627-2642, 2017.

[10] Q. M. Anstee, G. Targher, and C. P. Day, "Progression of NAFLD to diabetes mellitus, cardiovascular disease or cirrhosis," Nature Reviews Gastroenterology \& Hepatology, vol. 10, no. 6, pp. 330-344, 2013.

[11] C. D. Byrne and G. Targher, "NAFLD: a multisystem disease," Journal of Hepatology, vol. 62, no. 1, pp. S47-S64, 2015.

[12] J. P. Ong, A. Pitts, and Z. M. Younossi, "Increased overall mortality and liver-related mortality in non-alcoholic fatty liver disease," Journal of Hepatology, vol. 49, no. 4, pp. 608-612, 2008.

[13] C. Estes, H. Razavi, R. Loomba, Z. Younossi, and A. J. Sanyal, "Modeling the epidemic of nonalcoholic fatty liver disease demonstrates an exponential increase in burden of disease," Hepatology, vol. 67, no. 1, pp. 123-133, 2018.

[14] J. Wattacheril, "Extrahepatic manifestations of nonalcoholic fatty liver disease," Gastroenterology Clinics of North America, vol. 49, no. 1, pp. 141-149, 2020.

[15] L. A. Adams, Q. M. Anstee, H. Tilg, and G. Targher, "Nonalcoholic fatty liver disease and its relationship with cardiovascular disease and other extrahepatic diseases," Gut, vol. 66, no. 6, pp. 1138-1153, 2017.

[16] G. Targher, G. Marchesini, and C. D. Byrne, "Risk of type 2 diabetes in patients with non-alcoholic fatty liver disease: causal association or epiphenomenon?" Diabetes \& Metabolism, vol. 42, no. 3, pp. 142-156, 2016.

[17] F. Bril and K. Cusi, "Management of nonalcoholic fatty liver disease in patients with type 2 diabetes: a call to action," Diabetes Care, vol. 40, no. 3, pp. 419-430, 2017.

[18] K. Cusi, "Role of obesity and lipotoxicity in the development of nonalcoholic steatohepatitis: pathophysiology and clinical implications," Gastroenterology, vol. 142, no. 4, pp. 711-725, 2012.

[19] R. Lomonaco, C. Ortiz-Lopez, B. Orsak et al., "Effect of adipose tissue insulin resistance on metabolic parameters and liver histology in obese patients with nonalcoholic fatty liver disease," Hepatology, vol. 55, no. 5, pp. 1389-1397, 2012.

[20] M. Ekstedt, L. E. Franzén, U. L. Mathiesen et al., "Long-term follow-up of patients with NAFLD and elevated liver enzymes," Hepatology, vol. 44, no. 4, pp. 865-873, 2006.

[21] R. Loomba, M. Abraham, A. Unalp et al., "Association between diabetes, family history of diabetes, and risk of nonalcoholic steatohepatitis and fibrosis," Hepatology, vol. 56, no. 3, pp. 943-951, 2012.

[22] A. Mantovani, C. D. Byrne, E. Bonora, and G. Targher, "Nonalcoholic fatty liver disease and risk of incident type 2 diabetes: a meta-analysis," Diabetes Care, vol. 41, no. 2, pp. 372-382, 2018.

[23] R. Zheng, Z. Du, M. Wang et al., "A longitudinal epidemiological study on the triglyceride and glucose index and the incident nonalcoholic fatty liver disease," Lipids Health Diseases, vol. 20, no. 1, p. 262, 2018.

[24] S. Ballestri, S. Zona, G. Targher et al., "Nonalcoholic fatty liver disease is associated with an almost twofold increased risk of incident type 2 diabetes and metabolic syndrome. Evidence from a systematic review and meta-analysis," Journal of Gastroenterology and Hepatology, vol. 31, no. 5, pp. 936-944, 2016.

[25] D.-H. Lee, M.-H. Ha, J.-H. Kim et al., "Gamma-glutamyltransferase and diabetes-a 4 year follow-up study," Diabetologia, vol. 46, no. 3, pp. 359-364, 2003.

[26] A. J. G. Hanley, K. Williams, A. Festa, L. E. Wagenknecht, R. B. D'Agostino, and S. M. Haffner, "Liver markers and development of the metabolic syndrome: the insulin resistance atherosclerosis study," Diabetes, vol. 54, no. 11, pp. 3140-3147, 2005.

[27] W. Goessling, J. M. Massaro, R. S. Vasan, R. B. D’Agostino, R. C. Ellison, and C. S. Fox, "Aminotransferase levels and 20year risk of metabolic syndrome, diabetes, and cardiovascular disease," Gastroenterology, vol. 135, no. 6, pp. 1935-1944, 2008.

[28] A. Fraser, R. Harris, N. Sattar, S. Ebrahim, G. Davey Smith, and D. A. Lawlor, "Alanine aminotransferase, 
-glutamyltransferase, and incident diabetes: the British women's heart and health study and meta-analysis," Diabetes Care, vol. 32, no. 4, pp. 741-750, 2009.

[29] A. L. Fracanzani, L. Valenti, E. Bugianesi et al., "Risk of severe liver disease in nonalcoholic fatty liver disease with normal aminotransferase levels: a role for insulin resistance and diabetes," Hepatology, vol. 48, no. 3, pp. 792-798, 2008.

[30] S. Ballestri, F. Nascimbeni, E. Baldelli et al., "Ultrasonographic fatty liver indicator detects mild steatosis and correlates with metabolic/histological parameters in various liver diseases," Metabolism, vol. 72, pp. 57-65, 2017.

[31] Q. Li, M. Dhyani, J. R. Grajo, C. Sirlin, and A. E. Samir, "Current status of imaging in nonalcoholic fatty liver disease," World Journal of Hepatology, vol. 10, no. 8, pp. 530-542, 2018.

[32] M. J. Armstrong, L. A. Adams, A. Canbay, and W.-K. Syn, "Extrahepatic complications of nonalcoholic fatty liver disease," Hepatology, vol. 59, no. 3, pp. 1174-1197, 2014.

[33] M. Shibata, Y. Kihara, M. Taguchi, M. Tashiro, and M. Otsuki, "Nonalcoholic fatty liver disease is a risk factor for type 2 diabetes in middle-aged Japanese men," Diabetes Care, vol. 30, no. 11, pp. 2940-2944, 2007.

[34] C.-H. Kim, J.-Y. Park, K.-U. Lee, J.-H. Kim, and H.-K. Kim, "Fatty liver is an independent risk factor for the development of type 2 diabetes in Korean adults," Diabetic Medicine, vol. 25 , no. 4 , pp. 476-481, 2008.

[35] J. C. Bae, E. J. Rhee, W. Y. Lee et al., "Combined effect of nonalcoholic fatty liver disease and impaired fasting glucose on the development of type 2 diabetes: a 4 -year retrospective longitudinal study," Diabetes Care, vol. 34, no. 3, pp. 727-729, 2011.

[36] K.-C. Sung, W.-S. Jeong, S. H. Wild, and C. D. Byrne, "Combined influence of insulin resistance, overweight/obesity, and fatty liver as risk factors for type 2 diabetes," Diabetes Care, vol. 35, no. 4, pp. 717-722, 2012.

[37] A. Kasturiratne, S. Weerasinghe, A. S. Dassanayake et al., "Influence of non-alcoholic fatty liver disease on the development of diabetes mellitus," Journal of Gastroenterology and Hepatology, vol. 28, no. 1, pp. 142-147, 2013.

[38] S. K. Park, M. H. Seo, H. C. Shin, and J.-H. Ryoo, "Clinical availability of nonalcoholic fatty liver disease as an early predictor of type 2 diabetes mellitus in Korean men: 5-year prospective cohort study," Hepatology, vol. 57, no. 4, pp. 1378-1383, 2013.

[39] S. Zelber-Sagi, D. Shoham, I. Zvibel, S. Abu-Abeid, O. Shibolet, and S. Fishman, "Predictors for advanced fibrosis in morbidly obese non-alcoholic fatty liver patients," World Journal of Hepatology, vol. 9, no. 2, pp. 91-98, 2017.

[40] G. Y. Chen, H. X. Cao, F. Li et al., "New risk-scoring system including non-alcoholic fatty liver disease for predicting incident type 2 diabetes in East China: shanghai Baosteel Cohort," Journal of Diabetes Investigation, vol. 7, no. 2, pp. 206-211, 2016.

[41] Y. Li, J. Wang, and Y. Tang, "Bidirectional association between nonalcoholic fatty liver disease and type 2 diabetes in Chinese population: evidence from the Dongfeng-Tongji cohort study," PLoS One, vol. 12, Article ID e0174291, 2017.

[42] J. Ma, S.-J. Hwang, A. Pedley et al., "Bi-directional analysis between fatty liver and cardiovascular disease risk factors," Journal of Hepatology, vol. 66, no. 2, pp. 390-397, 2017.

[43] M. Liu, J. Wang, J. Zeng, X. Cao, and Y. He, "Association of NAFLD with diabetes and the impact of BMI changes: a 5year cohort study based on 18,507 elderly," The Journal of Clinical Endocrinology \& Metabolism, vol. 102, no. 4, pp. 1309-1316, 2017.
[44] W.-S. Lv, R.-X. Sun, and Y.-Y. Gao, "Nonalcoholic fatty liver disease and microvascular complications in type 2 diabetes," World Journal of Gastroenterology, vol. 19, no. 20, pp. 31343142, 2013.

[45] C. A. Silaghi, H. Silaghi, A. E. Craciun et al., "Age, abdominal obesity, and glycated hemoglobin are associated with carotid atherosclerosis in type 2 diabetes patients with nonalcoholic fatty liver disease," Medical Ultrasonography, vol. 17, no. 3, pp. 300-307, 2015.

[46] A. Mantovani, A. Rigamonti, S. Bonapace et al., "Nonalcoholic fatty liver disease is associated with ventricular arrhythmias in patients with type 2 diabetes referred for clinically indicated 24-hour Holter monitoring," Diabetes Care, vol. 39, no. 8, pp. 1416-1423, 2016.

[47] K. Guo, L. Zhang, J. Lu et al., "Non-alcoholic fatty liver disease is associated with late but not early atherosclerotic lesions in Chinese inpatients with type 2 diabetes," Journal of Diabetes and Its Complications, vol. 31, no. 1, pp. 80-85, 2017.

[48] M. Yi, R.-P. Chen, R. Yang, and H. Chen, "Increased prevalence and risk of non-alcoholic fatty liver disease in overweight and obese patients with type 2 diabetes in South China," Diabetic Medicine, vol. 34, no. 4, pp. 505-513, 2017.

[49] X. Ding, Y. Xu, and Y. Wang, "Nonalcoholic fatty liver disease and associated metabolic risks of hypertension in type $2 \mathrm{di}-$ abetes: a crosssectional community-based study," International Journal of Endocrinology, vol. 2017, Article ID 526256, , 2017.

[50] I. Sporea, R. Mare, A. Popescu et al., "Screening for liver fibrosis and steatosis in a large cohort of patients with type 2 diabetes using vibration controlled transient elastography and controlled attenuation parameter in a single-center real-life experience," Journal of Clinical Medicine, vol. 9, no. 4, p. 1032, 2020.

[51] European Association for the Study of the Liver (EASL); European Association for the Study of Diabetes (EASD); European Association for the Study of Obesity (EASO), "EASL-EASD-EASO clinical practice Guidelines for the management of non-alcoholic fatty liver disease," Journal of Hepatology, vol. 64, no. 6, pp. 1388-1402, 2016.

[52] American Diabetes Association, "Improving care and promoting health in populations: standards of medical care in Diabetes 2019," Diabetes Care, vol. 42, no. 1, pp. S7-S12, 2019.

[53] N. Chalasani, Z. Younossi, J. E. Lavine et al., "The diagnosis and management of non-alcoholic fatty liver disease: practice guideline by the American association for the study of liver diseases, American college of gastroenterology, and the American gastroenterological association," Hepatology, vol. 55, no. 6, pp. 2005-2023, 2012. 